\title{
Anti-apoptotic PI3K/Akt signaling by sodium/glucose transporter 1 reduces epithelial barrier damage and bacterial translocation in intestinal ischemia
}

\author{
Ching-Ying Huang ${ }^{1}$, Jong-Kai Hsiao ${ }^{2}$, Yen-Zhen Lu', Tsung-Chun Lee ${ }^{3}$ and Linda C-H Yu ${ }^{1}$
}

Intestinal ischemia/reperfusion (I/R) causes mucosal barrier damage and bacterial translocation (BT), leading to septic complications. Previous in vitro studies showed that activation of sodium/glucose transporter 1 (SGLT1) prevented the epithelial apoptosis and permeability rise induced by microbial products. Our aim was to investigate whether luminal glucose uptake by SGLT1 protects against ischemia-induced epithelial cell death and barrier dysfunction, and to explore the glucose-mediated cellular survival pathways in vivo. Rat jejunum was luminally instilled with either vehicle, a pancaspase inhibitor ZVAD, or glucose prior to I/R challenge (occlusion of the superior mesenteric artery for 20 min and reperfusion for $60 \mathrm{~min}$ ). Histopathology and apoptosis in the jejunum were examined by TUNEL staining and caspase-3 cleavage. Intestinal permeability was evaluated using in vivo assays measuring luminal-to-blood passage of fluoresceindextran and portal drainage of enterally administered gadodiamide by magnetic resonance imaging. BT was determined by culturing liver and spleen homogenates. Immunofluorescent analysis and kinase assay were used to study PI3K/Akt signaling pathways. Intestinal I/R caused enterocyte apoptosis and villous destruction. Intestinal infusion with ZVAD decreased the I/R-triggered gut permeability rise and BT, suggesting that the barrier damage was partly dependent on cell apoptosis. Enteral instillation of glucose attenuated the epithelial apoptosis, barrier damage, and mucosal inflammation caused by I/R. Phloridzin (a SGLT1 inhibitor) reduced the protective effect of glucose in a dose-dependent manner. Enteral glucose increased the mucosal Akt kinase activity as evidenced by the augmented phosphorylation of exogenous GSK3. Enhanced membrane translocation and phosphorylation of Akt in epithelial cells were associated with elevated phosphorylation of mTOR, Bad, and FoxO1/3a following glucose uptake. Inhibition of PI3K/Akt signaling by LY294002 and wortmannin partially blocked the glucose-mediated rescue of cell apoptosis and barrier damage. In conclusion, SGLT1 glucose uptake alleviated I/R-induced barrier dysfunction and BT, partly by inhibiting epithelial apoptosis via activation of PI3K/Akt signaling.

Laboratory Investigation (2011) 91, 294-309; doi:10.1038/labinvest.2010.177; published online 25 October 2010

KEYWORDS: bacterial translocation; cytoprotection; enterocyte apoptosis; glucose; ischemia/reperfusion; signal transduction

Intestinal ischemia/reperfusion (I/R) injury can occur in patients with mesenteric artery embolism or severe trauma, and in those undergoing bowel transplantation or other major vascular and abdominal surgery. Mesenteric I/R may lead to the development of sepsis, systemic inflammatory response syndrome, and multiple organ failure. ${ }^{1,2} \mathrm{~A}$ high in-hospital mortality rate of $60-80 \%$ was reported in patients with acute mesenteric ischemia. ${ }^{2,3}$ The disruption of blood supply during ischemia reduces the delivery of oxygen and glucose to tissues, and the subsequent restoration of blood flow stimulates the production of oxidative free radicals. ${ }^{4,5}$ Although much is known about oxidative stress, its management during intestinal I/R-related emergencies remains challenging.

The intestinal lumen contains over 100 trillion commensal bacteria that are separated from the rest of the body by a barrier of epithelial cells connected via tight junctions. ${ }^{6,7}$ However, gut barrier damage manifested by enhanced bacterial translocation (BT) has been documented in animal models of mesenteric I/R. ${ }^{8,9}$ Enteric bacteria have a crucial

\footnotetext{
${ }^{1}$ Graduate Institute of Physiology, National Taiwan University College of Medicine, Taipei, Taiwan, ROC; ${ }^{2}$ Department of Medical Imaging, National Taiwan University Hospital, Taipei, Taiwan, ROC and ${ }^{3}$ Division of Gastroenterology, Department of Internal Medicine, National Taiwan University Hospital, Taipei, Taiwan, ROC

Correspondence: Dr L C-H Yu, PhD, Graduate Institute of Physiology, National Taiwan University College of Medicine, Suite 1020, No. 1 Jen-Ai Road Section I, Taipei 100, Taiwan, ROC.

E-mail: Ichyu@ntu.edu.tw or Ichyuyu@hotmail.com

Received 1 April 2010; revised 18 August 2010; accepted 24 August 2010
} 
role in the pathogenesis of I/R-induced local inflammation and remote organ dysfunction. ${ }^{10,11}$ It is known that increased intestinal permeability may result from disruption of tight junctions in the epithelial cells because of energy depletion and cell death. ${ }^{12-14}$ Clear evidence of cell apoptosis can be seen in I/R-challenged intestinal mucosa. ${ }^{15-17}$ However, whether epithelial apoptosis is directly responsible for triggering gut leakiness and BT is still under debate.

Sodium-dependent glucose transporter 1 (SGLT1) is the main mediator of apical glucose uptake, whereas at the basolateral membrane the glucose transporter GLUT2 facilitates diffusive transport of intracellular glucose into the bloodstream. ${ }^{18}$ Our previous studies demonstrated that activation of SGLT1 rescued enterocytes from cell apoptosis and the permeability change stimulated by bacterial endotoxin and by parasitic products in vitro. ${ }^{14,19,20}$ SGLT1 glucose uptake inhibited the cytosolic release of mitochondrial cytochrome $c$ and prevented the activation of caspase- 3 in human intestinal Caco-2 cells via an unknown mechanism. ${ }^{14}$ A more recent report showed that initiation of $\mathrm{Na}^{+}$/glucose cotransport by SGLT1 triggered downstream Akt signaling for regulation of cellular functions. ${ }^{21} \mathrm{~A}$ critical role of PI3K/ Akt signaling in resistance to apoptosis has been reported in multiple cell types. ${ }^{22,23}$ Studies have shown that PI3K/Akt phosphorylates and thereby inactivates Bad (a proapoptotic mitochondrial $\mathrm{Bcl}-2$ family protein) or phosphorylates mTOR that then activates $\mathrm{p} 70^{\mathrm{S} 6 \mathrm{~K}}$ to phosphorylate Bad. ${ }^{22,23}$ Other downstream targets of Akt that are involved in regulating cell survival and cell cycle progression include $\mathrm{I} \kappa \mathrm{B} \alpha /$ $\mathrm{NF} \kappa \mathrm{B}$, glycogen synthase kinase 3 (GSK3), and Forkhead family of transcription factors (FoxOs). ${ }^{24-27}$ It is still unknown whether glucose uptake via SGLT1 alleviates I/R-induced pathological cell death and barrier damage. At this point, the cellular survival pathways responsible for the glucose protective mechanism in the intestines remain incompletely understood.

The aims of this study were to (1) investigate whether epithelial apoptosis is a cause of intestinal barrier damage upon ischemic insult; (2) evaluate the protective effects of SGLT1-mediated glucose uptake against epithelial apoptosis, bacterial influx, and mucosal inflammation in $\mathrm{I} / \mathrm{R}$ injury; and (3) assess the role of PI3K/Akt signaling pathways in the mechanism of the cytoprotective effects afforded by glucose.

\section{MATERIALS AND METHODS} Intestinal I/R

Male Wistar rats (250-300 g) were raised in a temperaturecontrolled room with 12-h light-dark cycles, and fed regular rat chow and water. Rats were fasted overnight with free access to water, and subjected to sham operation or mesenteric $\mathrm{I} / \mathrm{R}$ challenge. In $\mathrm{I} / \mathrm{R}$ rats, the superior mesenteric artery (SMA) was occluded with an atraumatic microvascular clamp for $20 \mathrm{~min}$ and then released for up to $60 \mathrm{~min}$. Ischemia of the bowel was verified by the loss of mesenteric pulsations and bluish discoloration of the jejunum. Sham controls rats received mock manipulation of SMA without occlusion. All animals were placed on heating pads to maintain body temperature at $37^{\circ} \mathrm{C}$ during the operation, and the heart rate was closely monitored. All protocols used in this study were approved and monitored by the institutional animal care and use committee, National Taiwan University.

\section{Experimental Design}

The experimental protocols were carried out under aseptic conditions. After anesthetization with urethane $(1.2 \mathrm{~g} / \mathrm{kg}$, intraperitoneal injection; Sigma-Aldrich, St Louis, MO, USA), all rats were subjected to midline laparotomy and a $10-\mathrm{cm}$ jejunal sac was created by thread ligature at both ends, beginning $10 \mathrm{~cm}$ distal to the ligament of Treitz in each animal. Care was taken not to occlude or puncture mesenteric vessels during the ligation. A $1 \mathrm{ml}$ syringe with a PE-10 catheter was intubated to one end of the jejunal sac and $0.5 \mathrm{ml}$ of Krebs buffer with the pancaspase inhibitor ZVAD (EMD Chemicals, Darmstadt, Germany) or glucose (Sigma) was carefully injected into the lumen. The formula for Krebs buffer was $115 \mathrm{mM} \mathrm{NaCl}, 8 \mathrm{mM} \mathrm{KCl}, 1.25 \mathrm{mM}$

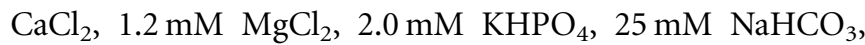
$\mathrm{pH}$ 7.33-7.37. Animals were then subjected to sham operation or $\mathrm{I} / \mathrm{R}$ challenge as described above.

Rats were randomly assigned to six groups $(n=6-8$ per group): group 1, sham controls that underwent laparotomy and whose jejunal lumen was instilled with Krebs buffer before sham operation; group 2 , sham $+Z$ rats that underwent laparotomy and whose jejunal lumen was instilled with $120 \mu \mathrm{M}$ ZVAD in Krebs buffer 30 min prior to sham operation; group 3 , sham $+\mathrm{G}$ rats that were enterally administered $25 \mathrm{mM}$ glucose in Krebs buffer immediately before sham operation; group 4, I/R rats that were enterally instilled with Krebs buffer before SMA occlusion for $20 \mathrm{~min}$ and reperfusion for $60 \mathrm{~min}$; group $5: \mathrm{I} / \mathrm{R}+\mathrm{Z}$ rats that were enterally instilled with $120 \mu \mathrm{M}$ ZVAD in Krebs buffer 30 min prior to the same $I / R$ procedure; and group $6, I / R+G$ rats that were enterally administered $25 \mathrm{mM}$ glucose in Krebs buffer immediately before I/R challenge. The concentrations of ZVAD and glucose used here have been previously shown to inhibit cell apoptosis induced by microbial products in epithelial cell cultures. ${ }^{14,20}$

In some experiments, phloridzin (a SGLT1 inhibitor; $0.5-2.5 \mathrm{mM}$ ) and phloretin (a GLUT2 inhibitor; 1.5 and $2.5 \mathrm{mM}$ ) were added to the glucose solution for enteral instillation prior to the $\mathrm{I} / \mathrm{R}$ procedure. In addition, to investigate the involvement of PI3K in the signaling pathways of glucose-mediated rescue mechanism, LY294002 $(10 \mathrm{mg} / \mathrm{kg})$ and wortmannin $(7.5 \mu \mathrm{g} / \mathrm{kg})$ were administered intraperitoneally and intravenously, respectively, $30 \mathrm{~min}$ before $\mathrm{I} / \mathrm{R}$ challenge in the presence of luminal glucose. At the end of the surgical procedures, the jejunal tissues, the liver, and the spleen were collected for experimental analysis. 


\section{Histopathological Scoring}

Jejunal segments were fixed in $4 \%$ paraformaldehyde, and care was taken to ensure proper orientation of the crypt to villus axis during embedding. Sections of $4 \mu \mathrm{m}$ thickness were stained with hematoxylin and eosin (H\&E). The degree of intestinal injury was evaluated using a light microscope and graded by two independent people blind to the actual treatment. Briefly, intestinal injury was scored from 0 to 5 according to the following criteria: grade 0 , normal mucosal villous structure; grade 1, presence of subepithelial space at villous tips; grade 2, scattered epithelial denudation on villous tips; grade 3 , denuded tips with exposed lamina propria and villous blunting; grade 4, epithelial shedding from both the apex and mid-region of the villi associated with shortened and widened villous structure; grade 5, complete destruction of villi and disintegration of lamina propria with ulceration.

\section{TUNEL Assay}

Paraffin-embedded jejunal sections were deparaffinized and in situ detection of cells with DNA-strand breaks was performed by the TUNEL labeling method using a TdT-FragEL ${ }^{\mathrm{TM}}$ DNA fragmentation detection kit (Oncogene Research Products, Boston, MA, USA) following the manufacturer's protocol. Negative controls were performed by substituting Tris-buffered saline (TBS) for the TdT enzyme.

\section{Caspase-3 Activity Assay}

Scraped jejunal mucosa was lysed and the protein concentration of the lysate was adjusted to $50 \mu \mathrm{g} / \mathrm{ml}$ to test for caspase-3 activity (Anaspec, San Jose, CA, USA). The assay is based on spectrophotometric detection of the chromophore rhodamine 110 (Rh110) after cleavage from the labeled substrate DEVD-Rh110. The caspase-3 activity of samples was measured in relative fluorescence units (RFUs) at $\mathrm{Ex} / \mathrm{Em}=496 \mathrm{~nm} / 520 \mathrm{~nm}$ for $60 \mathrm{~min}$ in 5 -min intervals. The level of caspase- 3 activity was expressed as RFU/min/mg.

\section{Ussing Chamber Studies and Macromolecular Flux Assay} Intestinal segments were excised and immediately placed in warm Krebs buffer. The external muscle layers were stripped off, leaving the submucosal plexus and mucosa intact. From each rat, two pieces of the muscle-stripped tissues (cut longitudinally into flat sheets along the mesenteric border) were mounted in Ussing chambers (WPI Instruments, Sarasota, FL, USA). Care was taken to avoid tissues containing Peyer's patches. The opening area $\left(2 \mathrm{~cm}^{2}\right)$ of the chamber exposed the tissue to $5 \mathrm{ml}$ of circulating oxygenated Krebs buffer. The serosal buffer contained $10 \mathrm{mM}$ glucose that was osmotically balanced with $10 \mathrm{mM}$ mannitol in the mucosal buffer. A circulating water bath maintained the temperature of the buffer at $37^{\circ} \mathrm{C}$. The serosal and mucosal tissue baths were clamped at $0 \mathrm{~V}$ using a voltage clamp feedback amplifier (WPI Instruments). The short-circuit current (Isc, $\mu \mathrm{A} / \mathrm{cm}^{2}$ ) of the tissue was recorded continuously on line. At 5-min intervals, the voltage between the two baths was stepped to $1 \mathrm{mV}$ for $1 \mathrm{~s}$, and the change in the Isc caused by the pulse was used to calculate the tissue conductance $\left(\mathrm{mS} / \mathrm{cm}^{2}\right)$ according to Ohm's law. ${ }^{28}$

The intestinal epithelial permeability was determined by the level of mucosal-to-serosal flux of horseradish peroxidase (HRP type II, MW $=44 \mathrm{kD}$; Sigma). Tissues in the Ussing chambers were allowed to equilibrate until the Isc stabilized before HRP was added to the luminal buffer at a final concentration of $5 \times 10^{-5} \mathrm{M}$. Samples $(300 \mu \mathrm{l})$ of serosal buffer were collected at $0,30,60$, and $90 \mathrm{~min}$ after luminal addition of HRP, and were replaced with Krebs buffer. The concentration of HRP was determined by a kinetic enzymatic assay. Fluxes were calculated according to standard formulae and were expressed as $\mathrm{pmol} / \mathrm{cm}^{2} / \mathrm{h} .{ }^{28}$

\section{Fluorescein-Based Gut Permeability Assay}

To assess gut permeability in vivo, a fluorescein-based assay was performed as described previously with slight modification. ${ }^{29}$ The $4-\mathrm{kDa}$ fluorescein isothiocyanate (FITC)conjugated dextran (FD4; Sigma) dissolved in Krebs buffer was administered into the lumen of ligated jejunal sac to a final concentration of $0.5 \mathrm{mg} / \mathrm{ml}$ immediately after the release of the artery clamp. The jejunal sac was placed back into the peritoneal cavity, and the open abdomen was covered with a saline-wetted gauze and foil to prevent evaporation and direct light. Arterial plasma from $0.5 \mathrm{ml}$ of blood was taken at $60 \mathrm{~min}$ post-reperfusion. Fluorescence intensity in arterial plasma was measured at $\mathrm{Ex} / \mathrm{Em}=496 / 520 \mathrm{~nm}$ using a plate reader. The concentration $(\mu \mathrm{g} / \mathrm{ml})$ of FD4 in plasma was calculated using a standard curve.

\section{Magnetic Resonance Imaging (MRI)-Based Gut Permeability Assay}

To assess gut permeability in vivo, the contrast agent gadodiamide (Omniscan; GE Healthcare) was instilled into the lumen of the ligated jejunal sac to a final concentration of $0.25 \mathrm{M}$ immediately after the release of the artery clamp, and the signal intensity of this agent in the liver and kidney was quantified using abdominal MRI as described previously. ${ }^{30}$ In sham controls, gadodiamide was injected into the jejunal sac after mock manipulation. The rats were placed in a home-made resonance coil with inner diameter of $6 \mathrm{~cm}$, and abdominal MRI was performed at various time points $(0,5,10,15,30,45$, and $60 \mathrm{~min})$ using a clinical $1.5 \mathrm{~T}$ MR System (Signa Excite; GE Healthcare). Two-dimensional T1-weighted fast spin echo MRI pulse sequences were used, with the following parameter set: $\mathrm{TR} / \mathrm{TE}=140 / 4.2 \mathrm{~ms}$, $\mathrm{FOV}=12 \times 8.4 \mathrm{~cm}^{2}$, and $\mathrm{NEX}=4$. The signal intensity produced by gadodiamide in the region of interest (ROI), liver and both kidneys, was measured. Signal-to-noise ratio (SNR) was calculated by dividing the signal intensity of the ROI by that of the background. To quantify the gadodiamide delivered to the systemic circulation, samples of plasma from $0.5 \mathrm{ml}$ of blood taken before $(t=0 \mathrm{~min})$ and 15,30 , and 
60 min after injecting gadodiamide were prepared. A known concentration $(0.5 \mathrm{M})$ of gadodiamide solution was serially diluted with neat plasma to prepare standard solutions for the calibration curve. Plasma and standard solutions were subjected to MRI scan, and imaging parameters were: $\mathrm{TR} / \mathrm{TE}=550 / 67.50 \mathrm{~ms}, \mathrm{FOV}=14 \times 0.5 \mathrm{~cm}^{2}$, and $\mathrm{NEX}=4$. The SNRs of the standard solutions of gadodiamide were plotted against their respective concentrations to establish a standard curve. The plasma gadodiamide concentrations were calculated from the standard curve. ${ }^{30}$

\section{Analysis of BT}

The liver and spleen tissues were homogenized, sonicated, and adjusted to a protein concentration of $0.1 \mathrm{~g} / \mathrm{ml}$ with sterile PBS. Each homogenate was inoculated onto fresh blood agar plates $(200 \mu \mathrm{l}$ per plate; Scientific Biotech, Taipei, Taiwan) and the plates were incubated at $37^{\circ} \mathrm{C}$ overnight. The number of bacterial colony-forming units (CFUs) was normalized per gram of tissue (CFU/g).

\section{Myeloperoxidase (MPO) Activity Assay}

Intestinal samples were homogenized and sonicated in 10 volumes of potassium phosphate buffer (PPB, $50 \mathrm{mM}$, $\mathrm{pH}$ 6.0) containing $0.5 \%$ HTAB (Sigma). Lysates were centrifuged and supernatants were diluted in PPB containing $0.167 \mathrm{mg} / \mathrm{ml}$ of O-dianisidine dihydrochloride (Sigma) and $0.0005 \%$ of $\mathrm{H}_{2} \mathrm{O}_{2}$. The enzyme concentration was determined from the absorbance at $460 \mathrm{~nm}$ measured every $30 \mathrm{~s}$ over a 5 -min period. One unit of MPO activity was defined as the quantity of enzyme degrading $1 \mu \mathrm{mol}$ of $\mathrm{H}_{2} \mathrm{O}_{2}$ per min, and MPO activity of the gut was expressed in $\mathrm{U} / \mathrm{mg}$ of tissue.

\section{ELISA for TNF- $\alpha$ and MIP-1 $\alpha$}

Scraped jejunal mucosa were homogenized and sonicated in PBS and the lysate was centrifuged. The protein concentration in the supernatant was quantified. The levels of TNF- $\alpha$ and MIP- $1 \alpha$ in mucosal samples were measured using ELISA development kits (PeproTech, Rocky Hill, NJ, USA) according to the manufacturer's instructions. To measure cytokine levels, microplates were coated overnight with capture antibodies. The plates were blocked with PBS containing $1 \%$ BSA for $1 \mathrm{~h}$ and washed. The sample and standard solutions were added and incubated for $2 \mathrm{~h}$. The biotinylated antigenaffinity detection antibodies were incubated for another $2 \mathrm{~h}$. After washing, avidin-HRP conjugate was added for $30 \mathrm{~min}$ followed by incubation with ABTS liquid substrate for color development. Absorbance was measured at $405 \mathrm{~nm}$ with correction set at $650 \mathrm{~nm}$. The cytokine levels in jejunal mucosa were expressed in $\mathrm{pg} / \mathrm{mg}$ of protein.

\section{Immunohistochemical and Immunofluorescence Staining}

Tissue sections were incubated with $3 \% \mathrm{H}_{2} \mathrm{O}_{2}$ to block endogenous peroxidase for immunohistochemical staining and were quenched with $50 \mathrm{mM} \mathrm{NH} \mathrm{NH}_{4} \mathrm{Cl}$ in $\mathrm{PBS}$ for immunofluorescence staining, and then blocked with $2 \%$ normal goat serum. Tissue sections were incubated with anti-cleaved caspase-3 (1:1000; Cell Signaling, Danvers, MA, USA), anti-proliferating cell nuclear antigen (PCNA) (1:100; Lifespan Biosciences, Seattle, WA, USA), anti-SGLT1 (1:200; Millipore, Billerica, MA, USA), anti-Akt (1:100; Cell Signaling), or isotype control antibodies. After washing with PBS, tissues stained for SGLT1 were incubated with biotinconjugated goat anti-rabbit IgG (1:1000; Molecular Probes, Carlsbad, CA, USA) for $1 \mathrm{~h}$, followed with a streptavidinconjugated Alexa Fluor 488 fluorescent probe (1:1000; Molecular Probes) for one hour; tissues stained for Akt were incubated with goat anti-mouse IgG conjugated to Alexa Fluor 488 fluorescent probe (1:1000; Molecular Probes) for $1 \mathrm{~h}$. All tissues were stained with Hoechst dye to visualize cell nuclei. Tissues stained for cleaved caspase-3 and PCNA were incubated with HRP-conjugated SignalStain Boost anti-rabbit IHC detection reagent (Cell Signaling) and developed with a DAB peroxidise substrate followed by counterstain with hematoxylin. The slides were mounted with aqueous mounting media and viewed under a Zeiss fluorescence microscope.

\section{Western Blotting}

Scraped jejunal mucosa was homogenized in ice-cold complete RIPA buffer, and the lysate was sonicated and centrifuged. The protein concentration of the supernatant was adjusted to $5 \mathrm{mg} / \mathrm{ml}$ and diluted in a $1: 1 \mathrm{vol} / \mathrm{vol}$ ratio in $2 \times$ electrophoresis sample buffer containing $2 \%(\mathrm{w} / \mathrm{v})$ SDS, $100 \mathrm{mM}$ DTT, and $62.5 \mathrm{mM}$ Tris/ $\mathrm{HCl}$ (pH 6.8). Samples were then heated to $95^{\circ} \mathrm{C}$ in a heat block for $5 \mathrm{~min}$, and stored at $-20{ }^{\circ} \mathrm{C}$ until used for immunoblotting.

The extracted proteins were separated by SDS-PAGE, and the resolved proteins were electrotransferred onto membranes. After blocking with 5\% non-fat milk in TBS, the membrane was incubated with anti-occludin (1:1000; Invitrogen), anti-Akt (1:500; Cell Signaling), anti-phosphoAkt (1:1000; Cell Signaling), anti-I $\kappa \mathrm{B} \alpha$ (1:1000; Santa Cruz, CA, USA), anti-phospho-I $\kappa \mathrm{B} \alpha$ (1:1000; Santa Cruz), antiphospho-Bad (1:500; Cell Signaling), anti-phospho-mTOR (1:500; Cell Signaling), anti-phospho-GSK3 $\alpha / \beta$ (1:1000; Cell Signaling), or anti-phospho-FoxO1/3a (1:1000; Cell Signaling) at $4{ }^{\circ} \mathrm{C}$ overnight. A monoclonal mouse anti- $\beta$-actin (1:10 000; Sigma) was also used to control for equal loading in each sample. Membranes were washed with $0.1 \%$ Tween20 in TBS and incubated with either horseradish peroxidaseconjugated goat anti-rabbit or anti-mouse IgG (1:1000; Cell Signaling). The antigens were revealed and band density quantified by photoimage analysis.

\section{Akt Kinase Activity}

The kinase activity of Akt was determined using a nonradioactive Akt kinase assay kit (Cell Signaling) according to the manufacturer's instruction. Briefly, scraped jejunal 

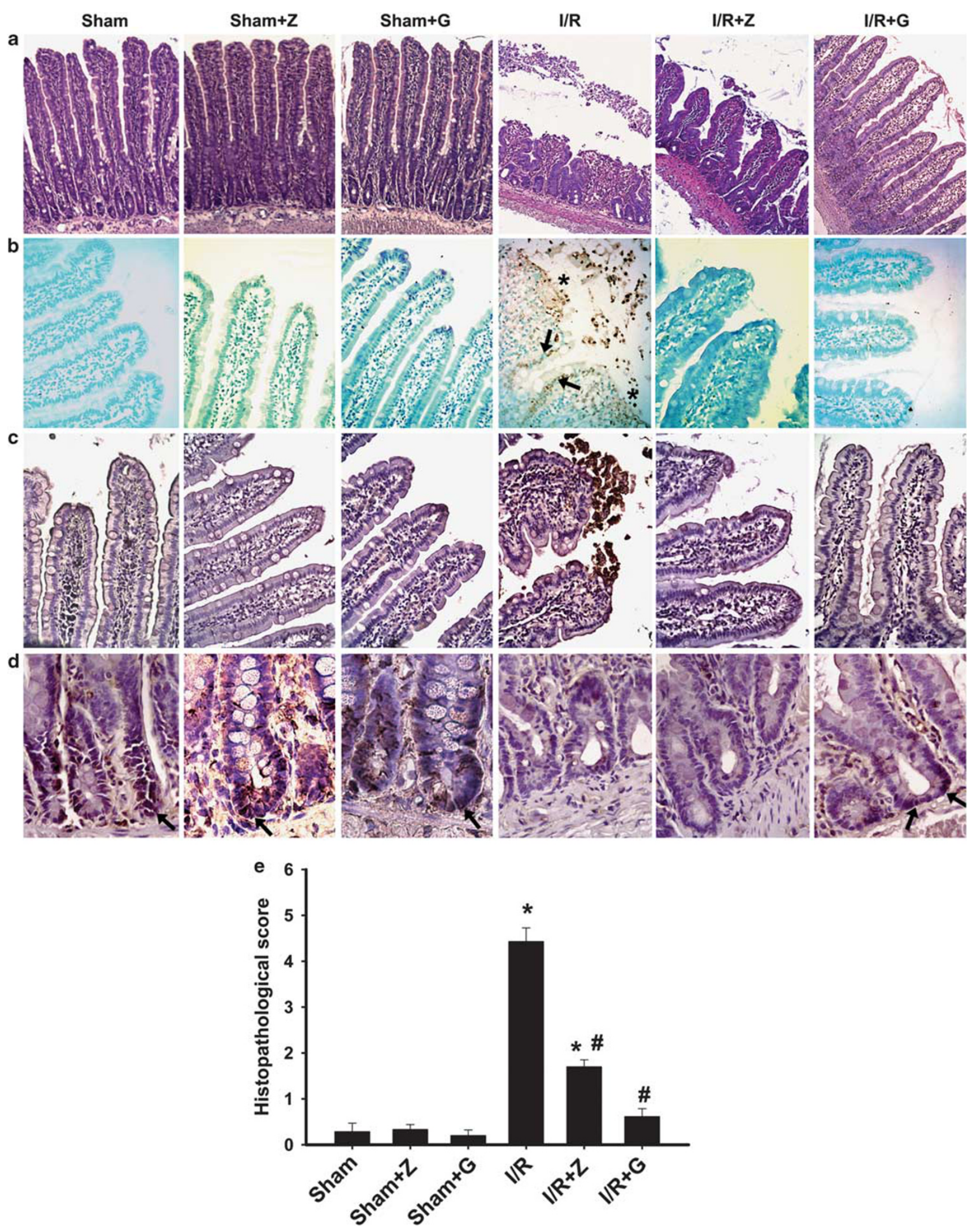
mucosa was homogenized in ice-cold lysis buffer, and the lysate was sonicated and centrifuged. For immunoprecipitation, $20 \mu \mathrm{l}$ of immobilized antibody beads conjugated to anti-phospho-Akt was added to $200 \mu$ l of cell lysate (the protein concentration was $2.25 \mathrm{mg} / \mathrm{ml}$ ) with gentle rocking overnight at $4{ }^{\circ} \mathrm{C}$. After washing with lysis buffer and kinase buffer, the pellet was incubated with ATP and GSK3 fusion protein for $30 \mathrm{~min}$ for kinase reaction. Exogenous GSK3, a downstream target of Akt, served as the substrate of phospho-Akt in this assay. The reaction was terminated by addition of $2 \times$ SDS sample buffer. The Akt kinase activity was determined by western blot using anti-phospho-GSK3 $\alpha / \beta$ antibody.

\section{Statistical Analysis}

All values except for bacterial $\mathrm{CFU} / \mathrm{g}$ were expressed as mean \pm s.e.m. and the means were compared by one-way analysis of variance followed by Student-Newman-Keul test. For the data of BT, pairwise ranking of the median of CFU/g values was conducted using the nonparametric MannWhitney $U$-test. Significance was established at $P<0.05$.

\section{RESULTS}

\section{Mesenteric I/R Triggers Intestinal Epithelial Apoptosis That Accompanies Villous Destruction}

Compared with non-ischemic tissues in sham controls, rats subjected to mesenteric I/R showed villous blunting and epithelial denudation in the jejunum (Figure 1a). Mucosal destruction was associated with increased number of TUNEL $(+)$ epithelial cells and enhanced immunoreactivity to cleaved caspase- 3 at regions close to the denuded villous tips in intestines of $I / R$ rats (Figure $1 b$ and $c$ ). Decreased immunoreactivity of PCNA was found in the intestinal crypts in $I / R$ rats compared with sham controls (Figure 1d). The severity of mucosal damage caused by $\mathrm{I} / \mathrm{R}$ was quantified by histopathological scoring (Figure 1e).

Enteral instillation of the pancaspase inhibitor ZVAD reduced the degree of mucosal injury and epithelial apoptosis caused by $I / R$ (Figure $1 \mathrm{a}-\mathrm{c}$, and $\mathrm{e}$ ). Normal intestinal histology was seen in sham-operated rats enterally administered ZVAD (Figure 1a). The mucosal caspase-3 activity was significantly increased after ischemia (Table 1). Luminal pretreatment with ZVAD inhibited both baseline and ischemia-induced mucosal caspase-3 activity (Table 1). This parameter was not measured post-reperfusion owing to the marked destruction of the villous structure.

To assess the changes in the tight junctional structure, the level of occludin was evaluated by western blot. Increased cleavage of occludin was seen in the intestinal mucosa of ischemic intestines compared with that of sham operation (Figure 2). Pretreatment with ZVAD diminished the level of occludin cleavage caused by ischemic challenge (Figure 2). Occludin levels were not examined post-reperfusion because of severe epithelial denudation.

\section{Increased Intestinal Permeability Caused by I/R Is Dependent on Epithelial Apoptosis}

The intestinal permeability changes caused by $\mathrm{I} / \mathrm{R}$ were first evaluated using an ex vivo assay that measured the luminal-

Table 1 Caspase-3 activity in the jejunal mucosa in rats

\begin{tabular}{lcccc}
\hline & Sham & I & I+Z & I+G \\
\hline Caspase-3 activity & $9800 \pm 1381$ & $15114 \pm 362^{*}$ & $94 \pm 7^{\star \#}$ & $11888 \pm 891^{\#}$ \\
(RFU/min per mg & & & & \\
protein) & & &
\end{tabular}

Rats were subjected to sham operation (sham) or ischemic (I) challenge for 20 min with or without enteral instillation of a pancaspase inhibitor ZVAD (Z) and glucose $(\mathrm{G})$.

${ }^{\star} P<0.05$ vs sham; ${ }^{*} P<0.05$ vs I ( $n=6$ per group).

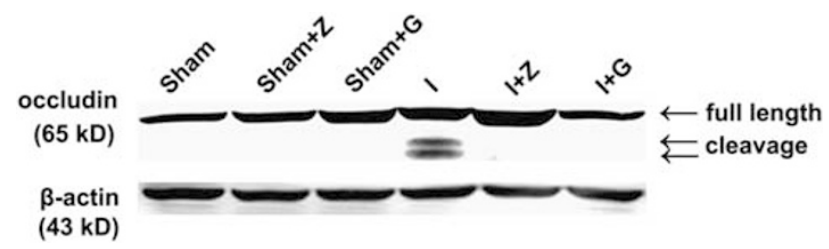

Figure 2 Increased cleavage of tight junctional occludin after ischemic challenge is alleviated by enteral instillation of ZVAD or glucose. Western blot images of occludin in jejunal mucosa of rats subjected to sham operation (Sham) and ischemic (I) challenge with or without enteral instillation of ZVAD (Z) or glucose (G). Representative images from four separate experiments; $n=4$ per group.

Figure 1 Mesenteric I/R triggers enterocytic apoptosis that accompanies villous destruction. The jejunal tissues of sham-operated and I/R rats were processed for (a) H\&E staining, (b) TUNEL assay, and immunostaining of (c) cleaved caspase-3, and (d) PCNA. Magnification: $\times 200$ in (a) and $\times 400$ in (b-d). (a) In comparison to nonischemic tissues in sham controls, mucosal injury including villous blunting and epithelial denudation were observed in $\mathrm{I} / \mathrm{R}$ rats. Enteral instillation of $120 \mu \mathrm{M}$ ZVAD (Z) or $25 \mathrm{mM}$ glucose (G) alleviated I/R-induced morphologic injury (labeled I/R $+Z$ and I/R $+\mathrm{G}$, respectively). Normal mucosal histology was seen in sham $+Z$ and sham $+G$ rats. (b) Enterocytes with increased TUNEL $(+)$ reaction were noted in regions close to the denuded villous apex after mesenteric I/R. TUNEL( + ) epithelial cells (arrows) and villous denudation (asterisks) were observed in the intestines of I/R rats. Enteral instillation of ZVAD or glucose decreased I/R-induced epithelial apoptosis. (c) Increased immunoreactivity to cleaved caspase-3 was seen at villous tips in I/R rats compared with sham controls. No staining was observed in intestinal tissues in sham $+Z$, sham $+G, I / R+Z$, and $I / R+G$ rats. (d) Immunoreactivity to PCNA (arrows) was detected in intestinal crypts in sham, sham $+Z$, and sham $+G$ rats. No staining was seen in intestinal tissues in $I / R$ rats. Enteral instillation of glucose attenuated the I/R-induced decrease of PCNA immunoreactivity, whereas ZVAD had no effect. (e) Histopathological scores in jejunal tissues of each group of rats. ${ }^{*} P<0.05$ vs sham, ${ }^{\#} P<0.05$ vs $\mathrm{I} / \mathrm{R} ; n=6$-8 per group. 
to-serosal flux of a macromolecular probe HRP in Ussing chambers. ${ }^{28}$ The transmural HRP flux rate in the intestine of I/R rats was twice that of sham controls. The increase of HRP flux in $\mathrm{I} / \mathrm{R}$ tissues compared with sham controls was evident at 30-60 and 60-90 min after luminal addition of HRP to the chambers (Figure 3a). a

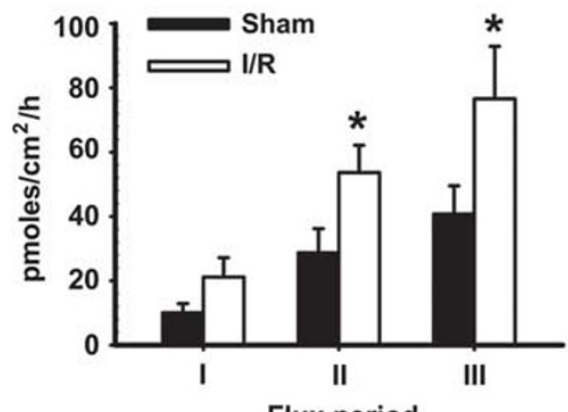

Flux period

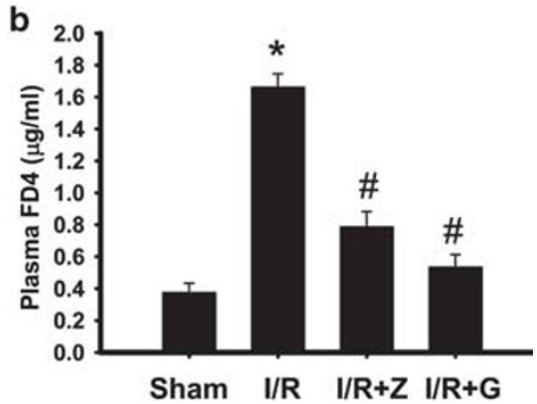

c

Sham

I/R
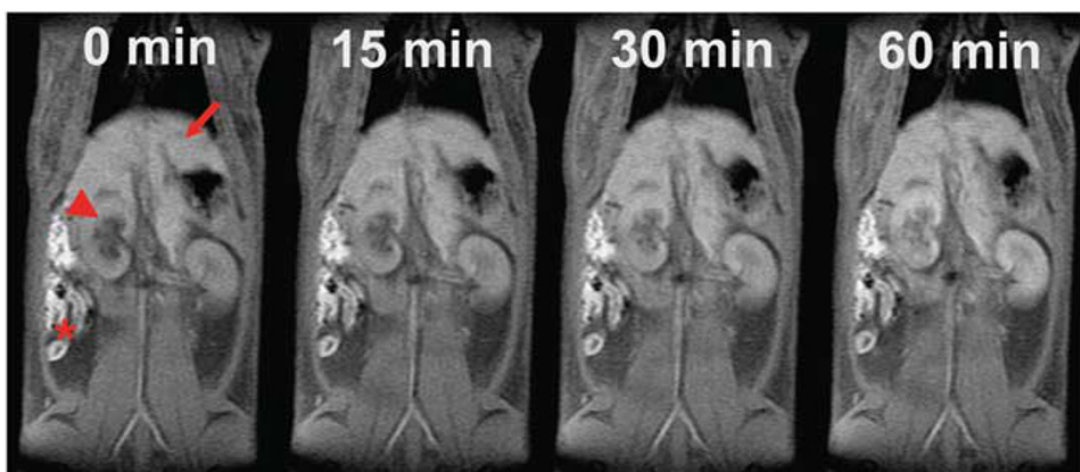

I/R+Z
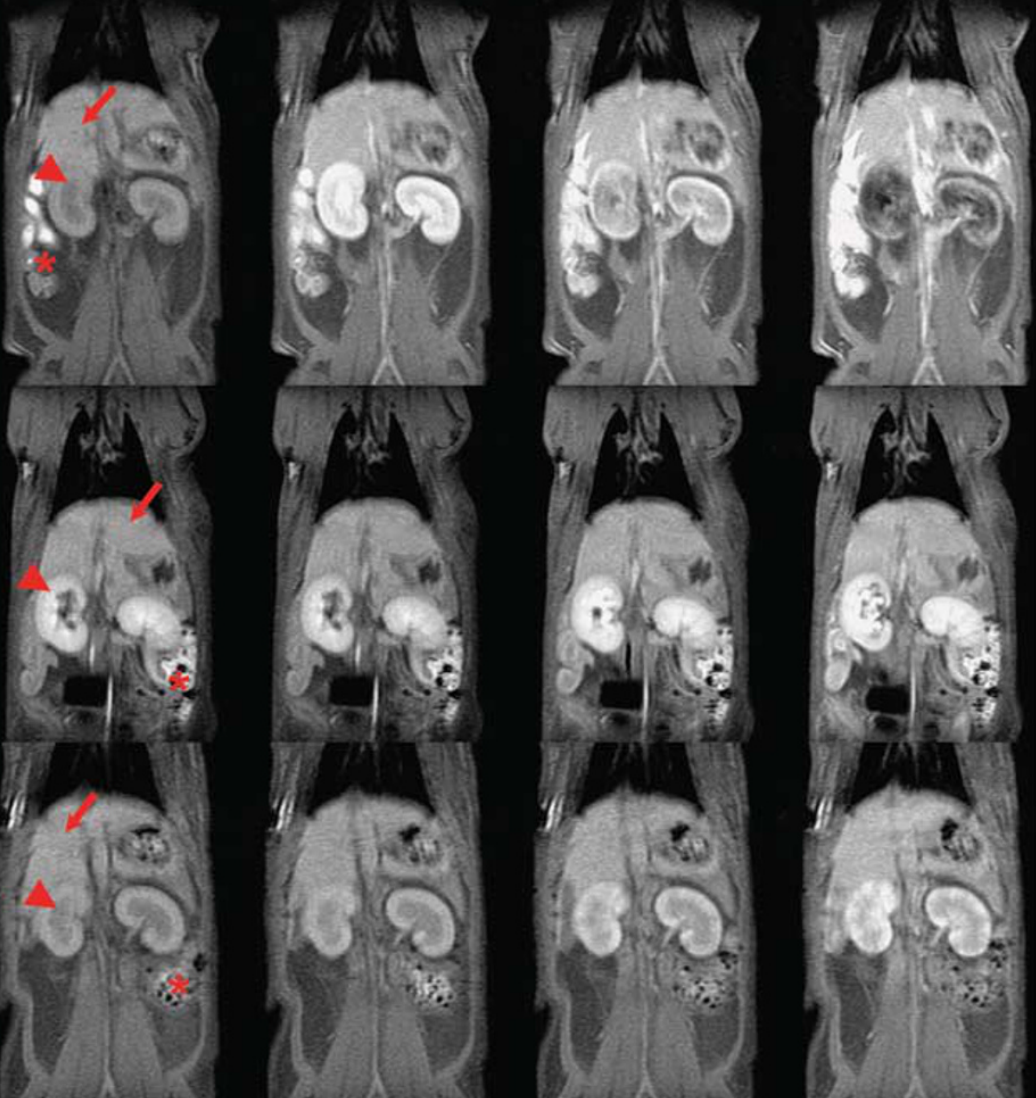

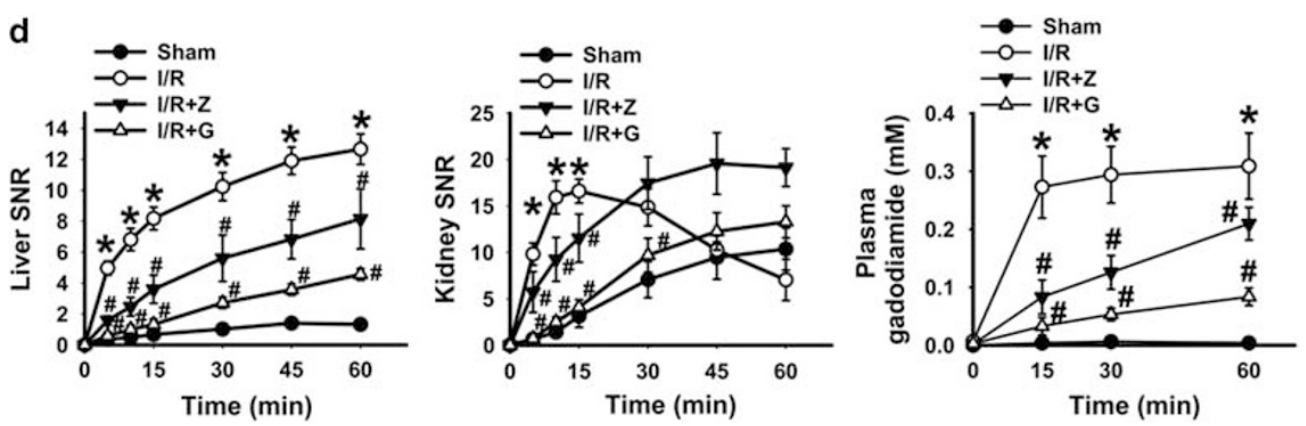

Figure 3 Continued.

In consideration of the time frame required to detect increased HRP flux and the extracorporeal setting of high oxygen and glucose supply needed to maintain the viability of tissues ex vivo-which may produce artificial results of the extent of $\mathrm{I} / \mathrm{R}$ injury-we also measured gut permeability changes in vivo by using ligated loops administered with fluorescein-conjugated dextran ${ }^{29}$ or a contrast agent gadodiamide for the newly developed MRI-based assay. ${ }^{30}$ A significant increase of the lumen-to-blood passage of FITC-dextran was seen in $\mathrm{I} / \mathrm{R}$ rats compared with sham controls (Figure 3b).

The novel MRI-based intestinal permeability assay monitors the portal drainage of an enterally administered contrast agent (gadodiamide) by quantifying the signals in the liver and kidney as the areas of interest. ${ }^{30}$ Representative abdominal images of sham and $\mathrm{I} / \mathrm{R}$ rats were taken at various time points after the start of reperfusion (Figure 3c). The signals in liver and kidney in $\mathrm{I} / \mathrm{R}$ rats were brighter than in sham controls (Figure 3c). The SNR of the areas of interest was quantified from the MR images (Figure 3d). The liver SNR values in sham controls was consistently low throughout these time points, whereas in $\mathrm{I} / \mathrm{R}$ rats the liver signals were significantly elevated over time and remained high up to 60 min post-reperfusion (Figure $3 \mathrm{~d}$ ). The signal intensity in liver was 14 times higher in $\mathrm{I} / \mathrm{R}$ rats $(\mathrm{SNR}=4.97 \pm 0.45)$ than in sham controls ( $\mathrm{SNR}=0.35 \pm 0.07$ ) as early as $5 \mathrm{~min}$ postreperfusion (Figure 3d). The kidney SNR values in $I / R$ rats were significantly higher than that of sham controls within 15 min post-reperfusion (Figure 3d). The plasma gadodiamide concentration was 68 times higher in $\mathrm{I} / \mathrm{R}$ rats than in sham controls (Figure 3d).
Pretreatment with intraluminal ZVAD partially decreased the gut permeability rise triggered by $I / R$, as evidenced by lower fluorescein intensity in plasma samples (Figure $3 \mathrm{~b}$ ), as well as lower SNR in the liver, kidney, and plasma in $\mathrm{I} / \mathrm{R}+\mathrm{Z}$ rats (Figure $3 \mathrm{c}$ and $\mathrm{d}$ ). The gut permeability in sham $+\mathrm{Z}$ rats was comparable to that of sham controls (data not shown).

\section{I/R-Induced Enteric BT and Mucosal Inflammation Are Diminished by Pretreatment with a Caspase Inhibitor}

The bacterial counts in liver tissue in I/R rats were significantly higher than sham controls (Figure 4a). A similar increase of bacterial CFUs was demonstrated in the spleen upon $\mathrm{I} / \mathrm{R}$ insult (Figure $4 \mathrm{~b}$ ). Intraluminal pretreatment with ZVAD abolished the increase in bacterial CFUs in the liver and spleen of $\mathrm{I} / \mathrm{R}$ rats (Figure $4 \mathrm{a}$ and $\mathrm{b}$ ).

The intestinal MPO activity (Figure 5) and the mucosal levels of TNF- $\alpha$ and MIP- $1 \alpha$ (Figure 6) were higher in ischemic intestines compared with those with sham operation, suggesting activation of inflammatory cells. Enteral instillation of ZVAD diminished the rise of MPO activity (Figure 5) and the increase of TNF- $\alpha$ and MIP- $1 \alpha$ production induced by ischemia (Figure 6). The inflammatory parameters in sham $+Z$ rats were comparable to those of sham controls (data not shown).

\section{Luminal Glucose Decreased I/R-Induced Intestinal Pathology}

Mucosal pathology and epithelial apoptosis

Enteral instillation of glucose significantly alleviated I/Rinduced mucosal injury, whereby the jejunal villi showed better structure and were covered by intact epithelial layers

Figure 3 I/R-triggered increase of epithelial permeability is ameliorated by enteral instillation of ZVAD or glucose. (a) Increased mucosal-to-serosal flux of HRP was seen in I/R rats compared with sham controls. HRP in serosal buffer was measured by kinetic enzymatic assay at 0-30 (I), 30-60 (II), and 60-90 (III) min after addition of HRP to the luminal buffer. ${ }^{*} P<0.05$ vs sham. (b) The 4-kDa FITC-dextran (FD4) concentration in plasma sample collected from sham, $\mathrm{I} / \mathrm{R}, \mathrm{I} / \mathrm{R}+\mathrm{Z}$, and $\mathrm{I} / \mathrm{R}+\mathrm{G}$ rats at 60 min post-reperfusion. A significant increase of the lumen-to-blood passage of FD4 was seen in $\mathrm{I} / \mathrm{R}$ rats compared with sham controls, which was decreased by instillation of ZVAD or glucose. (c) Abdominal images of sham, $I / R, I / R+Z$, and $I / R+G$ rats were taken at $0,15,30$, and $60 \mathrm{~min}$ post-reperfusion. The arrow, arrowhead, and asterisk indicate the location of the liver, kidney, and ligated jejunal sac, respectively. In all panels, ' 0 min' indicates images taken before luminal gadodiamide was instilled into the jejunal sacs. (d) SNRs in the liver, kidney, and plasma samples were higher in $\mathrm{I} / \mathrm{R}$ rats than in sham controls. The $\mathrm{I} / \mathrm{R}$-induced increase of gut permeability was ameliorated by enteral instillation of $Z \mathrm{VAD}$ or glucose. ${ }^{\star P}<0.05 \mathrm{vs}$ sham; ${ }^{\#} P<0.05$ vs $\mathrm{I} / \mathrm{R} ; n=5$ to 6 per group. 

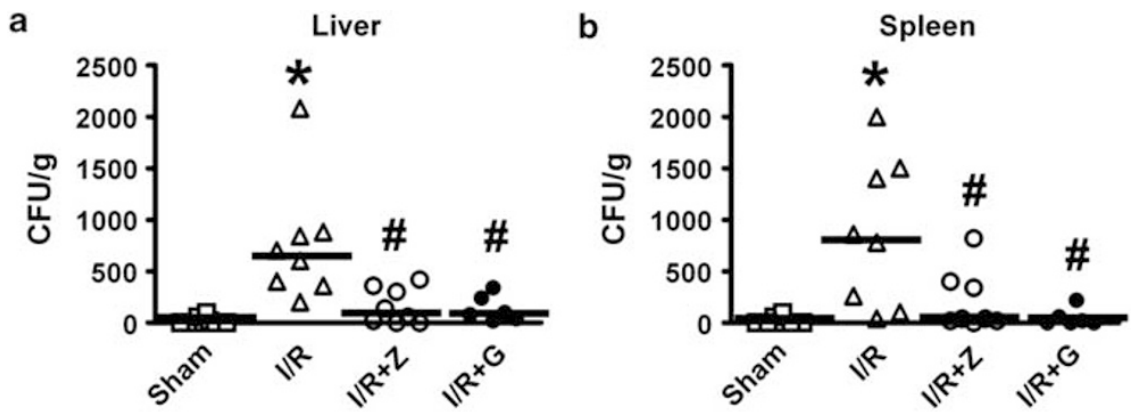

Figure 4 I/R-induced enteric bacterial translocation is diminished by ZVAD or glucose. The numbers of bacterial CFUs in liver (a) and spleen (b) of sham, $I / R, I / R+Z$, and $I / R+G$ rats were normalized to tissue weight. Each data point in the figure represents the value from one animal. The median values of bacterial counts (shown as bars) were significantly higher in I/R rats than in sham controls. The increase in bacterial counts caused by $\mathrm{I} / \mathrm{R}$ was reduced by luminal instillation of ZVAD or glucose. ${ }^{\star} P<0.05$ vs sham; ${ }^{\sharp} P<0.05$ vs $\mathrm{I} / \mathrm{R} ; n=6-8$ per group.

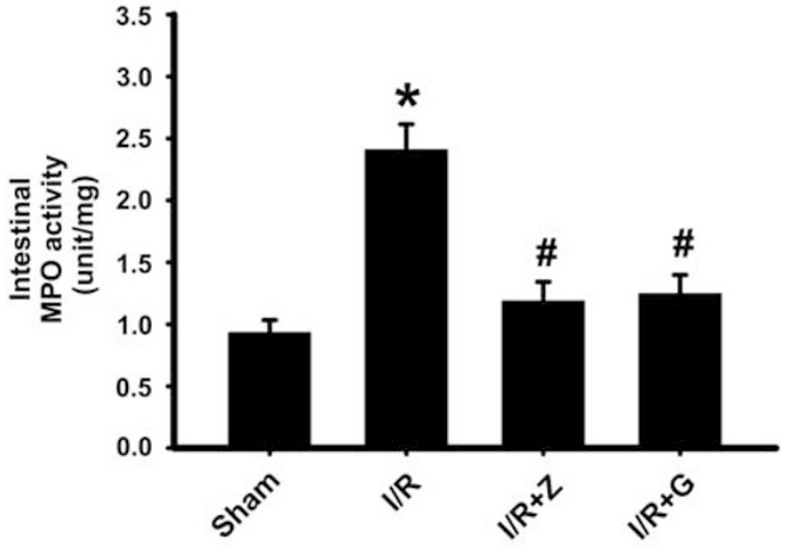

Figure 5 Increased MPO activity caused by $\mathrm{l} / \mathrm{R}$ is reduced by enteral instillation of ZVAD or glucose. The jejunal tissues of sham, $I / R, I / R+Z$, and $\mathrm{I} / \mathrm{R}+\mathrm{G}$ rats were processed for the measurement of MPO activity (see Materials and Methods). One unit of MPO activity was defined as the quantity of enzyme degrading $1 \mu \mathrm{mol}$ of $\mathrm{H}_{2} \mathrm{O}_{2}$ per min. ${ }^{\star} P<0.05$ vs sham; ${ }^{\#} P<0.05$ vs $\mathrm{I} / \mathrm{R} ; n=6-8$ per group.

without cell apoptosis, and the crypt regions showed PCNA immunoreactivity (Figure 1a-d). Normal intestinal histology was seen in sham $+G$ rats (Figure 1a). Luminal glucose also reduced the increase in mucosal caspase- 3 activity caused by intestinal ischemia (Table 1).

\section{Tight junctional integrity and epithelial permeability}

The effect of glucose on intestinal barrier function was examined further. Enteral instillation of glucose reduced the level of occludin cleavage in ischemic guts (Figure 2).

Moreover, the presence of luminal glucose during $\mathrm{I} / \mathrm{R}$ challenge diminished the lumen-to-blood passage of FITCdextran (Figure $3 \mathrm{~b}$ ), as well as the gadodiamide signals and SNR in the liver, kidney, and plasma samples (Figure 3c and $\mathrm{d}$ ).

\section{$B T$ and mucosal inflammation}

The I/R-triggered increase of BT was abolished by luminal glucose. The bacterial counts in liver and spleen were sig- nificantly lower in $\mathrm{I} / \mathrm{R}+\mathrm{G}$ rats than in $\mathrm{I} / \mathrm{R}$ rats (Figure $4 \mathrm{a}$ and b). The bacterial counts in sham $+G$ rats were comparable to those of sham controls (data not shown).

The intestinal MPO activity in $\mathrm{I} / \mathrm{R}+\mathrm{G}$ rats was decreased compared with I/R rats (Figure 5). Reduced mucosal levels of TNF- $\alpha$ and MIP- $1 \alpha$ were seen in ischemic intestines instilled with enteric glucose (Figure $6 \mathrm{a}$ and $\mathrm{b}$ ). The intestinal inflammatory parameters in sham $+G$ rats were comparable to those of sham controls (data not shown).

\section{Phloridzin Blockage of SGLT1 Sugar Uptake Nullifies Glucose Protection in a Dose-Dependent Manner}

To verify the role of SGLT1 in the protective mechanism, pharmacological inhibitors of specific transporters were instilled into the ligated sac in the presence of glucose and the gut permeability changes were measured by MRI-based assay. We found that luminal pretreatment with phloridzin (a specific SGLT1 inhibitor; 0.5-2.5 mM) dose dependently increased the liver SNR values of $\mathrm{I} / \mathrm{R}+\mathrm{G}$ rats to levels comparable to those of $\mathrm{I} / \mathrm{R}$ rats (Figure $7 \mathrm{a}$ ). Phloridzin $(2.5 \mathrm{mM})$ also inhibited the glucose-mediated reduction of BT (Figure 7b). On the other hand, pretreatment with phloretin (an inhibitor of GLUT2; $2.5 \mathrm{mM}$ ) did not diminish the protective effect of glucose on gut permeability (Figure 7a) and BT (Figure 7b). Moreover, apical expression of SGLT1 was confirmed in the jejunal epithelium in sham controls (Figure 7c). A lack of SGLT1 staining accompanied the epithelial sloughing seen in $\mathrm{I} / \mathrm{R}$ rat intestines; the presence of luminal glucose abolished this decrease (Figure 7c).

\section{PI3K/Akt Signaling Is Involved in the Glucose-Mediated Cell Survival Mechanism}

To verify the involvement of PI3K/Akt signals in the glucosemediated cytoprotective mechanism, $\mathrm{I} / \mathrm{R}+\mathrm{G}$ rats were administered LY294002 (LY) or wortmannin (W), which partially eliminated the glucose protection against I/Rinduced cell apoptosis and villous destruction (Figure 8a) as well as permeability rise (Figure $8 \mathrm{~b}$ ). 

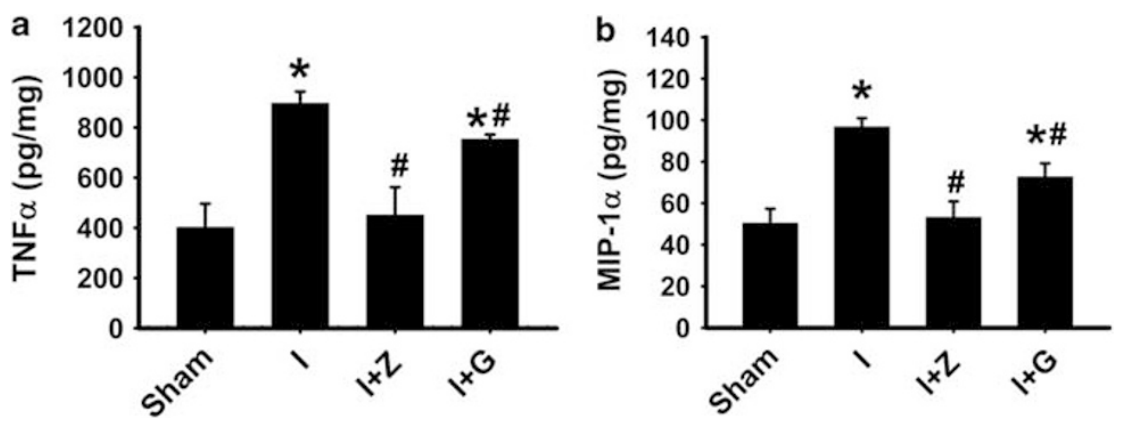

Figure 6 Ischemic challenge augments the production of proinflammatory cytokines in gut mucosa. (a) Mucosal levels of TNF- $\alpha$, which increased after ischemic challenge, were attenuated by luminal instillation of ZVAD or glucose. (b) The increase of mucosal MIP-1 $\alpha$ levels induced by ischemic challenge was ameliorated by ZVAD or glucose. ${ }^{*} P<0.05$ vs sham; $P<0.05$ vs ; $n=6$ per group.

The activation status of Akt in gut mucosa was investigated by measuring the kinase reaction of immunoprecipitated phospho-Akt to phosphorylate exogenous GSK3 in an in vitro assay. Decreased Akt activity in the intestinal mucosa of $\mathrm{I} / \mathrm{R}$ rats was evidenced by the lower levels of phosphorylated GSK3 in I/R samples than in sham groups (Figure 9a). Enteral instillation of glucose increased the mucosal Akt activity in both sham and I/R tissues (Figure 9a). The GSK3 phosphorylation levels in samples from $I / R+G+L Y$ rats was lower than $I / R+G$ rats (Figure $9 b$ ), indicating that specific inhibition of PI3K by LY294002 partly diminished the glucose-mediated activation of Akt. Furthermore, immunofluorescent staining demonstrated the cytosolic expression of Akt in jejunal epithelial cells in sham controls (Figure 9c, A). Enteral instillation of glucose induced the translocation of cytosolic Akt to the brush border and subcellular organelles of enterocytes in sham $+\mathrm{G}$ rats (Figure 9c, B). The loss of Akt expression was correlated with the sloughing of intestinal epithelium in $\mathrm{I} / \mathrm{R}$ rats (Figure $9 \mathrm{c}, \mathrm{C}$ ), in which these changes were attenuated by the addition of luminal glucose (Figure 9c, D). The phenomenon of Akt translocation to the brush border and to subcellular organelles in epithelial cells was also seen in $I / R+G$ rats (Figure $9 c, D$ ).

The phosphorylation levels of Akt and downstream signals such as $\mathrm{I} \kappa \mathrm{B}, \mathrm{mTOR}, \mathrm{Bad}$, and FoxO1/3a in the mucosa of ischemic tissues were investigated by western blot. These parameters were not measured post-reperfusion because of severe mucosal denudation. A significant decrease in phosphorylated Akt level was seen in ischemic tissues compared with sham controls (Figure 10a). Increased phosphorylation of Akt was seen after enteral instillation of glucose in both sham and ischemic tissues (Figure 10a). Recent data indicate a link between Akt and $\mathrm{I} \kappa \mathrm{B} \alpha / \mathrm{NF} \kappa \mathrm{B}$ signals in promotion of cell survival and resistance to apoptosis in enterocytes. ${ }^{24,25}$ On the other hand, $\mathrm{I} \kappa \mathrm{B} \alpha / \mathrm{NF} \kappa \mathrm{B}$ signals also have key roles in proinflammatory cytokine production in monocytes/ macrophages and intestinal epithelial cells. ${ }^{31-34}$ Our data showed that the mucosal level of phospho-I $\kappa \mathrm{B} \alpha$ was significantly increased after ischemic challenge compared with sham controls (Figure 10b). Enteral instillation of glucose diminished the increase of $\mathrm{I} \kappa \mathrm{B} \alpha$ phosphorylation caused by ischemia (Figure 10b). Lastly, the phosphorylation of Akt correlated with the phosphorylation of mTOR, Bad, and FoxO1/3a in ischemic tissues with glucose instillation (Figure 10c).

\section{DISCUSSION}

Our results demonstrate that enterocytic apoptosis is in part responsible for triggering intestinal barrier dysfunction upon $\mathrm{I} / \mathrm{R}$ challenge. The histological findings suggest that mesenteric I/R triggers epithelial apoptosis that accompanies villous disintegration and decreased crypt cell proliferation. Changes in intestinal permeability in I/R rats were demonstrated by the transmural HRP flux rate ex vivo and by the lumento-blood passage of enterally administered FD4 and gadodiamide in vivo. The increase of epithelial permeability paralleled the augmentation of BT in I/R intestines, indicating gut barrier damage. These pathological changes were attenuated by enteral instillation of ZVAD, providing direct evidence that epithelial apoptosis is in part responsible for triggering intestinal barrier damage and bacterial influx. This study is thus the first to demonstrate that modification of epithelial caspase activity reduces intestinal permeability and BT in animals. We also showed that pretreatment with ZVAD diminished the increase of MPO activity and the production of TNF- $\alpha$ and MIP- $1 \alpha$ in ischemic intestines, suggesting that epithelial apoptosis and barrier dysfunction preceded mucosal inflammation.

The intestinal permeability was evaluated using ex vivo and in vivo assays. A twofold increase of the transmural HRP flux was observed in the intestinal tissues in $\mathrm{I} / \mathrm{R}$ rats compared with sham controls. However, the increased HRP flux was only evident at 30-60 and 60-90 min after the addition of the probe to Ussing chambers; the delayed observation and the extracorporeal, oxygenated setting may produce artificial results of the extent of $\mathrm{I} / \mathrm{R}$ injury. In light of these technical limitations, we also evaluated gut permeability in vivo by measuring the luminal-to-blood passage of enterally administered FD4 or gadodiamide during the reperfusion period. The plasma level of FD4 was four times higher in 

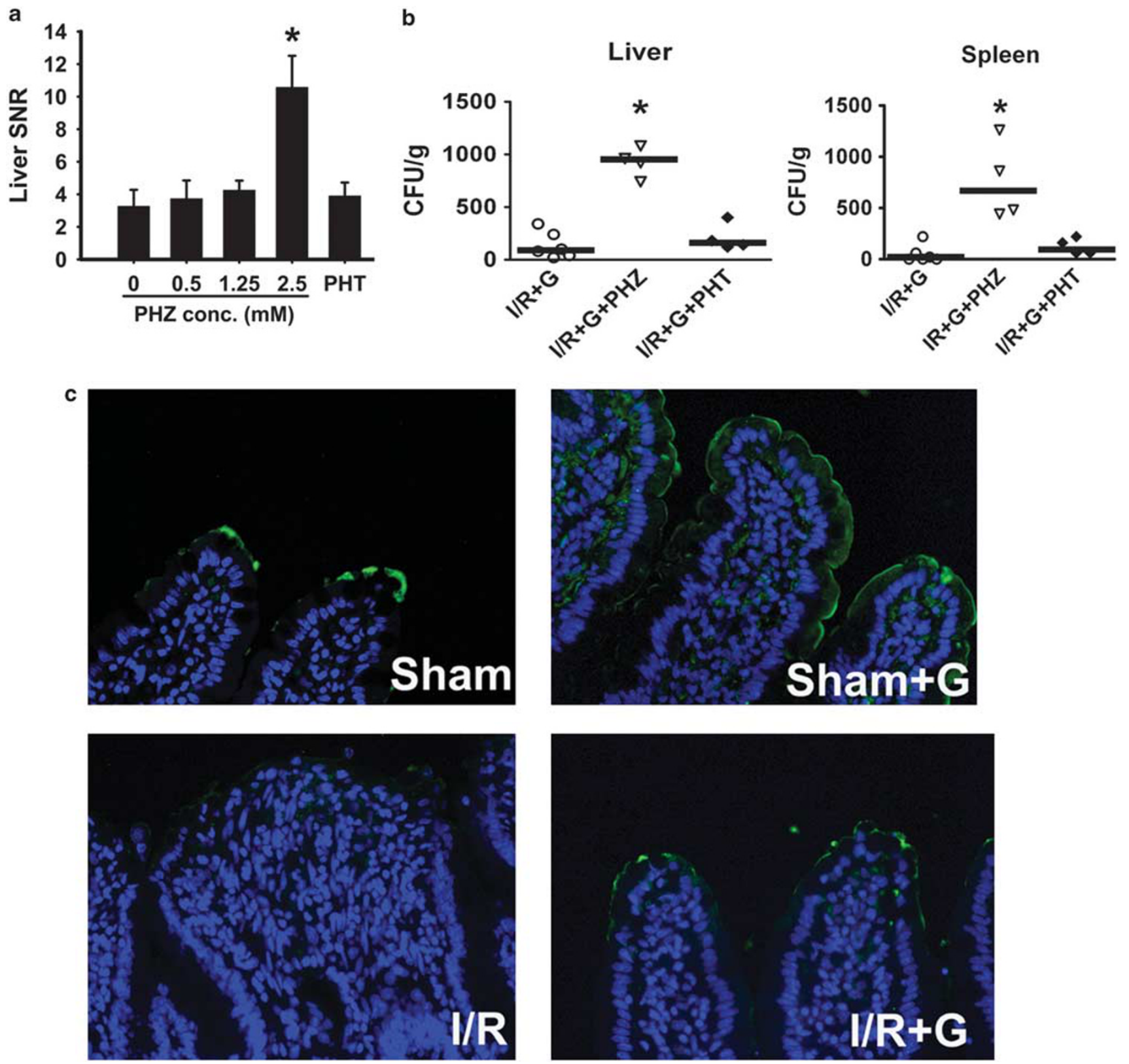

Figure 7 Blockage of phloridzin-sensitive SGLT1 inhibits the glucose protection against I/R-increased epithelial permeability and bacterial translocation. (a) Administration of phloridzin ( $\mathrm{PHZ}$ ) increased the liver SNR in $\mathrm{I} / \mathrm{R}+\mathrm{G}$ rats to a comparable level to $\mathrm{I} / \mathrm{R}$ rats in a dose-dependent manner. The liver SNR values were acquired at $60 \mathrm{~min}$ post-reperfusion. Phloretin (PHT) had no effect on the liver SNR values in $\mathrm{I} / \mathrm{R}+\mathrm{G}$ rats. ${ }^{*} P<0.05$ vs $0 \mathrm{mM}$ phloridzin. (b) Glucose-mediated reduction of BT to liver and spleen was abolished by phloridzin (PHZ; $2.5 \mathrm{mM}$ ), but not phloretin (PHT; $2.5 \mathrm{mM}$ ). The bar represents the median of bacterial counts in each group. ${ }^{*} P<0.05 \mathrm{vs} \mathrm{I} / \mathrm{R}+\mathrm{G}$. (c) Immunofluorescent staining demonstrated the apical expression of SGLT1 (green color) on jejunal villi of sham, sham $+G$, and I/R $+G$ rats. Lack of SGLT1 staining was correlated with epithelial sloughing in the intestine in $I / R$ rats. The cell nuclei are stained blue; $n=4-6$ per group.

$\mathrm{I} / \mathrm{R}$ rats than in sham controls, indicating compromised intestinal barrier function after ischemic challenge. A novel MRI-based assay developed previously from our laboratory was used to detect the real-time permeability changes in vivo. This more sensitive assay showed a five- to ten-fold increase of SNR in liver and kidney in ischemic rats at the early phase $(<15 \mathrm{~min}$ ) of reperfusion, supporting the hypothesis that it is an acute break of the epithelial barrier that leads to aug- mented portal drainage of luminal probes. The kidney SNR peaked at $15 \mathrm{~min}$ post-reperfusion and declined afterwards, which was likely because of the high concentration of gadodiamide in the renal medulla and calyces, leading to a greater T2 shortening effect than T1 shortening effect. These results are in agreement with others showing increased gut permeability upon I/R challenge. ${ }^{35,36}$ In comparison to the HRP flux assay and the fluorescence intensity test, this MRI-based 

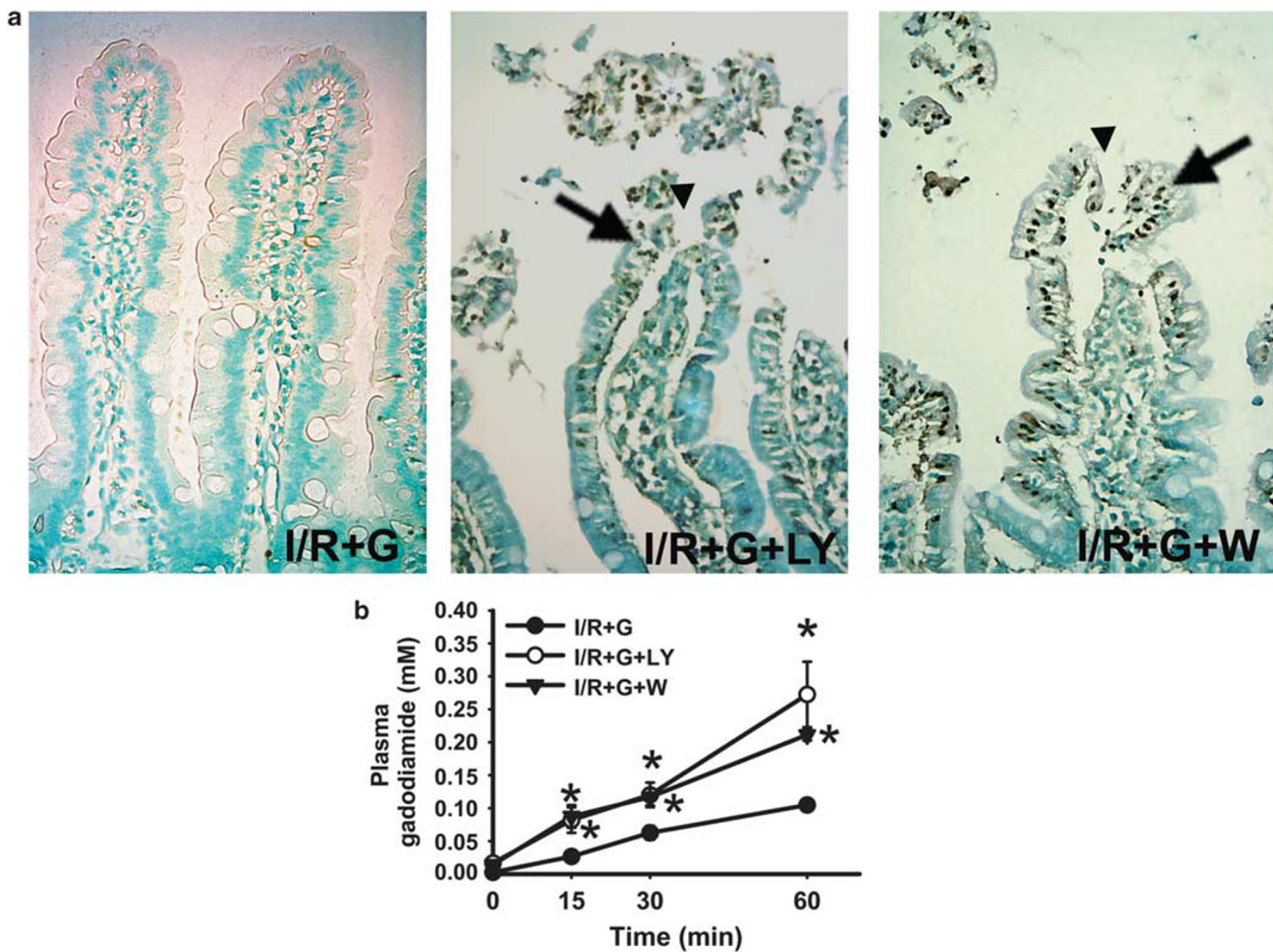

Figure 8 Antiapoptotic PI3K signaling is involved in the mechanism of glucose protection against I/R-induced intestinal permeability rise. (a) Inhibition of PI3K by LY294002 (LY) or wortmannin (W) blocked the glucose rescue from cell apoptosis caused by I/R. TUNEL( + ) epithelial cells (arrows) and disruption of epithelial continuity (arrowheads) were noted in I/R $+\mathrm{G}+\mathrm{LY}$ and $\mathrm{I} / \mathrm{R}+\mathrm{G}+\mathrm{W}$ rats. Magnification: $\times 400$. (b) The plasma gadodiamide concentrations in $\mathrm{I} / \mathrm{R}+\mathrm{G}+\mathrm{LY}$ and $\mathrm{I} / \mathrm{R}+\mathrm{G}+\mathrm{W}$ rats were higher than that of $\mathrm{I} / \mathrm{R}+\mathrm{G}$ rats, indicating that PI3K inhibitors partially diminished the glucose protection against $\mathrm{I} / \mathrm{R}$-induced increase of epithelial permeability. ${ }^{\star} P<0.05$ vs $\mathrm{I} / \mathrm{R}+\mathrm{G} ; n=6$ per group.

method is fast and sensitive, allows us to rapidly detect changes in gut permeability, and provides a means for further studies of targeted pharmacological intervention.

Physiological cytoprotective mechanisms contributing to resistance against apoptosis include upregulation of glucose transporters (eg, SGLT1, GLUT1, and GLUT4) and maintenance of high intracellular glucose concentration. ${ }^{14,19,20,37-40}$ The phenomenon of glucose protection has been documented in a number of cell types, including neurons, leukocytes, myocardiocytes, and vascular smooth muscle cells. ${ }^{37-40}$ Previous in vitro studies utilizing human intestinal epithelial Caco-2 cells have also demonstrated that SGLT1 glucose uptake inhibits cell apoptosis and barrier impairment caused by bacterial and parasitic products. ${ }^{14,19,20}$ Based on our finding that epithelial apoptosis is partly responsible for intestinal barrier dysfunction upon I/R challenge, we sought to investigate the use of glucose supplementation to correct excessive cell death and to improve gut barrier integrity. In
I/R rats, glucose uptake mediated by the phloridzin-sensitive SGLT1 protected the intestinal epithelium from apoptosis and attenuated the increase in permeability and BT, leading to diminished inflammatory responses. Taken together with previous studies, ${ }^{14,19,20}$ our finding suggests that SGLT1mediated cytoprotection may operate under a number of metabolic and microbial stress conditions.

The signal transduction pathways responsible for promoting cell survival were also investigated. Membrane translocation and increased phosphorylation of Akt in villous epithelial cells were paralleled by enhanced Akt kinase activity in the gut mucosa following glucose uptake by SGLT1. This finding is consistent with previous studies showing that Akt is a downstream step of a signaling pathway induced by $\mathrm{Na}^{+}$/ glucose cotransport, ${ }^{21,41}$ which triggered the activation of $\mathrm{Na}^{+} / \mathrm{H}^{+}$exchanger (NHE). Our pharmacological blockade studies with LY294002 and wortmannin confirmed that $\mathrm{PI} 3 \mathrm{~K} / \mathrm{Akt}$ activation is involved in the glucose-mediated 

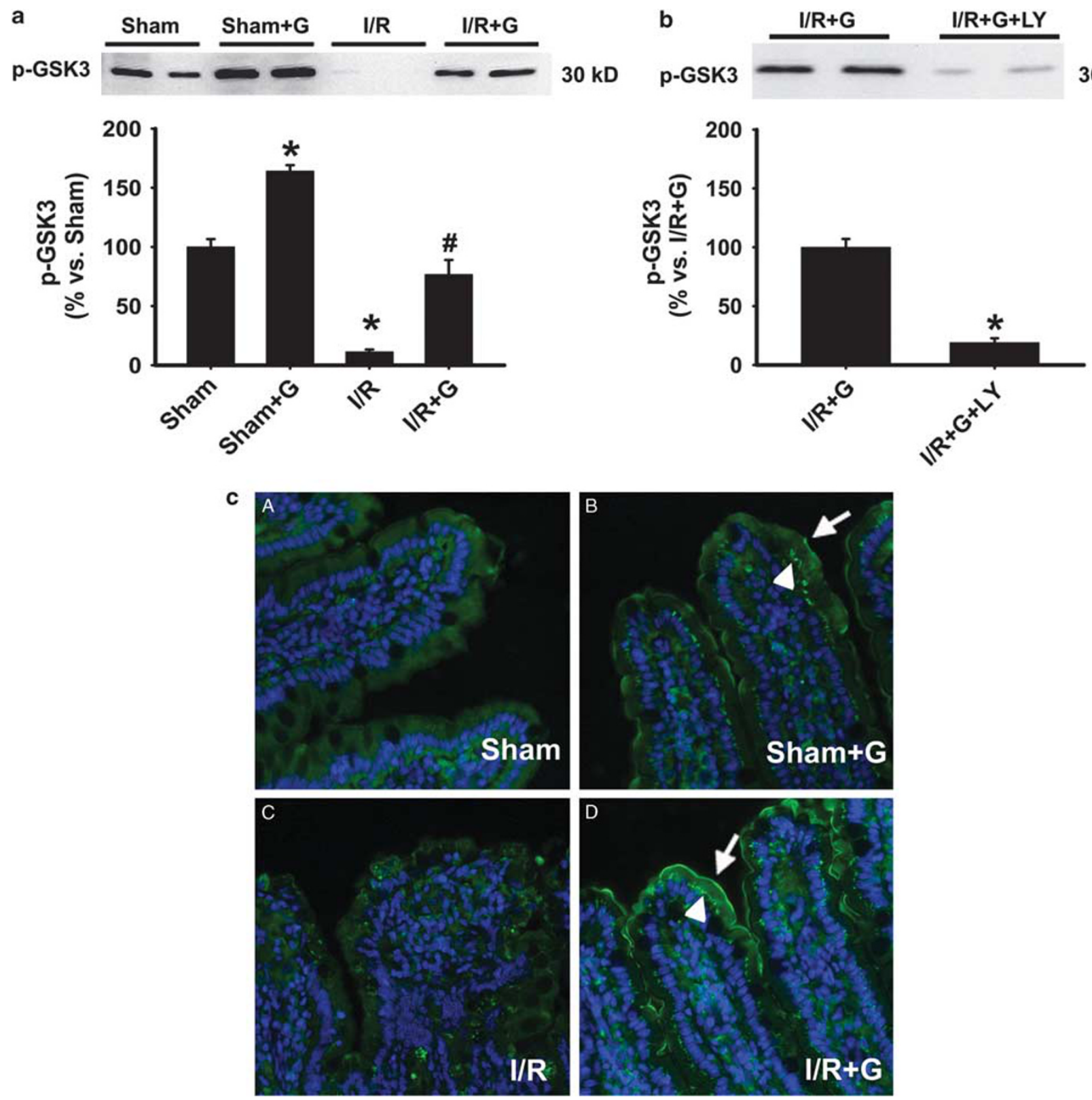

Figure 9 l/R-decreased mucosal Akt activity is inhibited by enteral instillation of glucose. Mucosal lysates from rat jejunal tissues were collected for the measurement of Akt activity. Phospho-Akt protein was immunoprecipitated from the mucosal lysates by anti-phospho-Akt antibody, and exogenous GSK3 served as a substrate for Akt kinase reaction in vitro. The level of phospho-GSK3 was examined by western blot. (a) Decreased Akt activity was seen in the intestinal mucosa of $\mathrm{I} / \mathrm{R}$ rats compared with sham controls. Luminal glucose increased the mucosal Akt activity in both sham and I/R rats. (b) Administration of a PI3K inhibitor LY294002 (LY) decreased the mucosal Akt activity in I/R $+\mathrm{G}$ rats. ${ }^{*} P<0.05 \mathrm{vs}$ sham; ${ }^{\#} P<0.05$ vs $\mathrm{I} / \mathrm{R} ; n=6$ per group. (c) Representative images of jejunal tissues stained for Akt (green color); cell nuclei are shown in blue. (A) Expression of cytosolic Akt was found in jejunal epithelial cells in sham controls. (B) Staining of Akt was noticed on brush border (arrows) and subcellular organelles (arrowheads) in villous epithelial cells in sham $+G$ rats. (C) Loss of Akt staining was correlated with epithelial sloughing in $1 / R$ rats. (D) Histological improvement and staining of Akt on brush border (arrows) and subcellular organelles (arrowheads) in enterocytes were seen in $\mathrm{l} / \mathrm{R}+\mathrm{G}$ rats.

protection against epithelial apoptosis, mucosal pathology, and gut barrier damage induced by I/R. Previous reports documented that PI3K/Akt signaling inhibits cell apoptosis by phosphorylating $\mathrm{Bad}$, either directly or indirectly via mTOR. ${ }^{23,42}$ A number of other downstream targets of Akt, such as $\mathrm{I} \kappa \mathrm{B} \alpha / \mathrm{NF} \kappa \mathrm{B} \alpha$, FoxO1/3a, and GSK3, are also involved in promoting cell survival and cell cycle progression. ${ }^{24-27} \mathrm{We}$ showed here that SGLT1 glucose uptake induced the phosphorylation of Akt and downstream targets such as mTOR, $\mathrm{Bad}$, and FoxO1/3a in intestinal mucosa. These results provide an explanation of the antiapoptotic effects of enteral glucose, which may contribute to cytoprotective mechanisms in intestinal I/R. It is noteworthy that recent evidence points to an unanticipated role of Bad in linking pathways of 


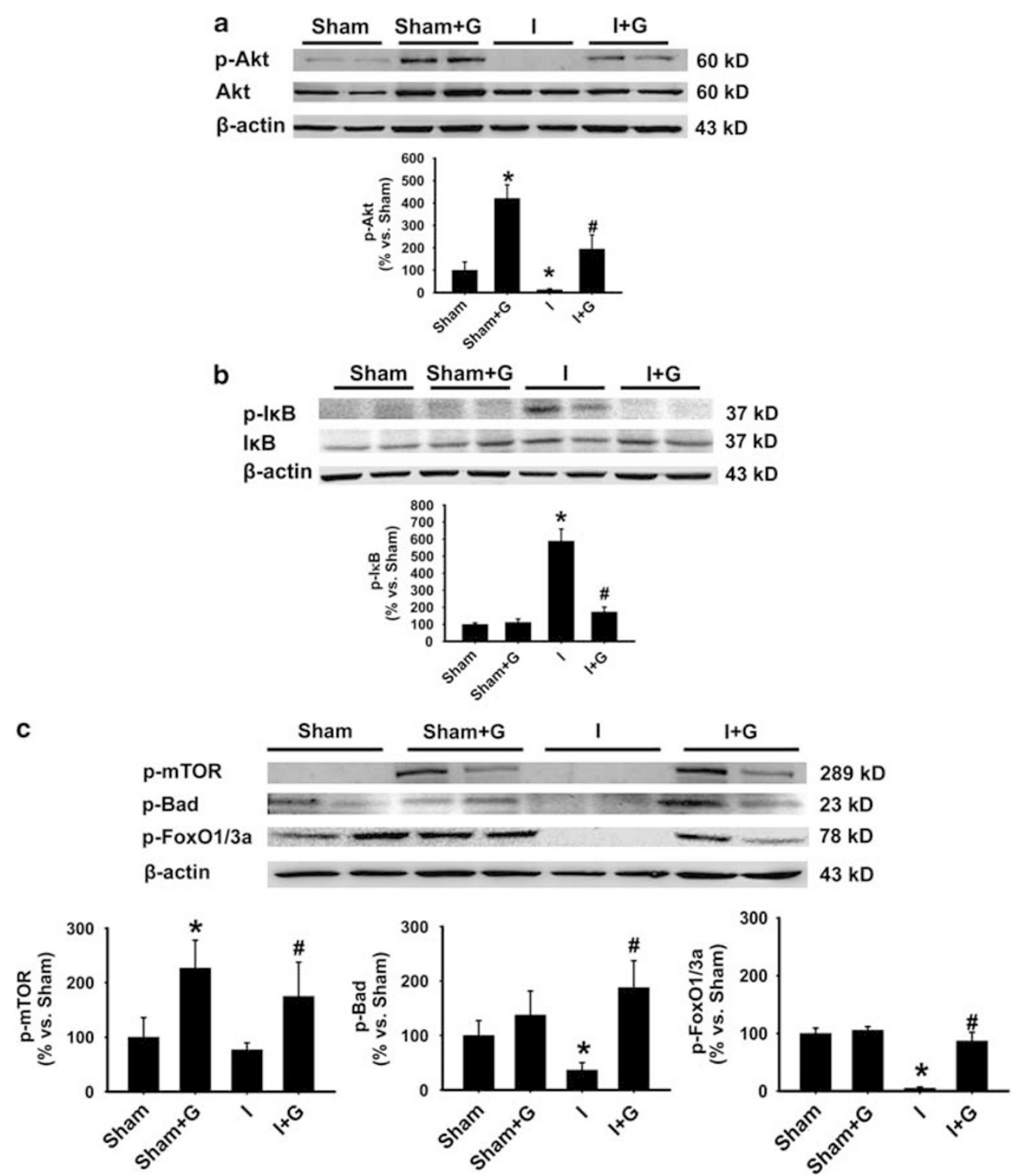

Figure 10 Enteral instillation of glucose induced the phosphorylation of Akt and downstream targets such as mTOR, Bad, and FoxO1/3a but not I $\kappa \mathrm{B} \alpha$ in ischemic intestines. Western blot showing the levels of phosphorylated $A k t, 1 \kappa B \alpha, m T O R$, Bad, and FoxO1/3a in jejunal mucosa of sham and ischemic rats after enteral instillation of glucose. Blots from three independent experiments were quantified by densitometry. (a) Decreased levels of phosphorylated Akt were seen in ischemic tissues compared with sham controls. Luminal glucose increased the phosphorylation of Akt in both sham and ischemic tissues. (b) Ischemic challenge augmented the phosphorylation levels of $I_{\kappa} \mathrm{B} \alpha$, which was decreased by glucose. (c) Luminal glucose increased the levels of phosphorylated mTOR, Bad, and FoxO1/3a in jejunal mucosa in ischemic rats. ${ }^{*} P<0.05$ vs sham; ${ }^{\#} P<0.05$ vs i; $n=6$ per group.

glucose metabolism and cell apoptosis. ${ }^{43,44}$ Danial et al ${ }^{43,44}$ demonstrated that Bad resides in a mitochondrial complex with glucokinase and participates in mitochondrial respiration in response to glucose. The phosphorylation status of Bad is associated with glucokinase activity; glucose deprivation results in dephosphorylation of Bad and Bad-dependent cell death. ${ }^{43,44}$ These findings highlight the role that mitochondrial Bad has in coordinating glucose metabolism and the apoptotic machinery. Whether the phosphorylation status of mitochondrial Bad affects the mode of glucose metabolism in ischemic intestines requires further investigation.
Recent reports indicated that the $\mathrm{I} \kappa \mathrm{B} \alpha / \mathrm{NF} \kappa \mathrm{B}$ pathway is involved in antiapoptotic events in intestinal epithelial cells against various pathogenic stimuli. ${ }^{45-47}$ However, our results demonstrated that instillation of enteric glucose decreased the levels of phosphorylated $\mathrm{I} \kappa \mathrm{B} \alpha$ in ischemic guts. Despite links between Akt and $\mathrm{I} \kappa \mathrm{B} \alpha / \mathrm{NF} \kappa \mathrm{B}$ pathways in the mechanism of cell survival, ${ }^{23-25}$ the $\mathrm{I} \kappa \mathrm{B} \alpha / \mathrm{NF} \kappa \mathrm{B}$ pathway is not involved in the glucose-mediated antiapoptotic signaling in intestinal epithelium. The upregulation of phospho-I $\kappa \mathrm{B} \alpha$ may be partly responsible for proinflammatory cytokine production after ischemic challenge. 
Overall, we demonstrated that SGLT1 glucose uptake in intestinal epithelial cells activated antiapoptotic pathways that involved PI3K/Akt signaling and increased phosphorylation of mTOR, Bad, and FoxO1/3a.

Accumulating data support the notion that SGLT1 orchestrates a number of fundamental cellular processes besides its canonical absorptive function. Previous reports showed that activation of SGLT1 induced the recruitment of GLUT2 to the brush border membrane for diffusive glucose transport via a PKC $\beta$-dependent pathway. ${ }^{48,49}$ Others documented that cotransport of $\mathrm{Na}^{+}$with glucose triggered the activation of Akt and phosphorylation of cytoskeleton-associated ezrin, leading to recruitment of NHE to apical membrane that facilitated absorption of sodium and hydrogen in intestines. ${ }^{21,41} \mathrm{~A}$ recent study by Palazzo et a ${ }^{50}$ demonstrated that activation of SGLT1 suppressed bacterial LPS-induced $\mathrm{NF} \kappa \mathrm{B}$ signaling in intestinal epithelial cells, and suggested that SGLT1 has a novel immunomodulatory role. Moreover, oral ingestion, but not intraperitoneal administration of glucose, attenuated proinflammatory cytokine production and protected endotoxemic mice from lethal septic shock. ${ }^{50}$ Clinically, oral rehydration therapy that targets SGLT1 to drive passive diffusion of water is a widely used supportive therapy for diarrheal patients. Early enteral nutrition (EN) is advocated for patients with multiple pathologies for its known benefit in lowering the risk of septic complications compared with parenteral supplementation. One area that has gained much attention in nutrition therapy nowadays is preoperative oral carbohydrate loading $(\mathrm{CHO}) .{ }^{51,52}$ This novel concept involves giving patients an isotonic carbohydrate solution at midnight the day before surgery and 2 to $3 \mathrm{~h}$ preoperatively, in contrast to the general routine of overnight fasting before surgery. Patients given $\mathrm{CHO}$ showed reduced postoperative insulin resistance and shorter hospital stay after colorectal resection. ${ }^{53}$ The advantage of early EN and CHO may also involve SGLT1-mediated nutritive and non-nutritive functions.

In conclusion, mesenteric $\mathrm{I} / \mathrm{R}$ induces epithelial apoptosis and mucosal damage, leading to the increase of gut permeability and bacterial influx. Glucose uptake mediated by SGLT1 attenuated the loss of intestinal barrier function partly via antiapoptotic PI3K/Akt signaling. Potential therapeutic interventions that target SGLT1 for promoting epithelial cell survival in diseases or surgical procedures with gut barrier damage warrant further investigation.

\section{ACKNOWLEDGEMENT}

This study was funded by the National Science Council, Taiwan, ROC (no. NSC95-2320-B-002-065-MY2 and no. NSC99-2320-B-002-024-MY3).

\section{DISCLOSURE/CONFLICT OF INTEREST}

The authors declare no conflict of interest.

1. Cerqueira NF, Hussni CA, Yoshida WB. Pathophysiology of mesenteric ischemia/reperfusion: a review. Acta Cir Bras 2005;20:336-343.
2. Yasuhara H. Acute mesenteric ischemia: the challenge of gastroenterology. Surg Today 2005;35:185-195.

3. Brandt $\amalg$, Boley SJ. AGA technical review on intestinal ischemia. American Gastrointestinal Association. Gastroenterology 2000;118:954-968.

4. Mallick IH, Yang W, Winslet MC, et al. Ischemia-reperfusion injury of the intestine and protective strategies against injury. Dig Dis Sci 2004;49: 1359-1377.

5. Yu LC. Protective mechanism against gut barrier dysfunction mesenteric ischemia/reperfusion. Adapt Med 2010;2:11-22.

6. O'Hara AM, Shanahan F. The gut flora as a forgotten organ. EMBO Rep 2006;7:688-693.

7. Leaphart $\mathrm{CL}$, Tepas III JJ. The gut is a motor of organ system dysfunction. Surgery 2007;141:563-569.

8. Aksoyek S, Cinel I, Avlan D, et al. Intestinal ischemic preconditioning protects the intestine and reduces bacterial translocation. Shock 2002; 18:476-480.

9. Kaneko $H$, Tamura A, Ishii $T$, et al. Bacterial translocation in small intestinal ischemia-reperfusion injury and efficacy of Anti-CINC antibody treatment. Eur Surg Res 2007;39:153-159.

10. Souza DG, Vieira AT, Soares AC, et al. The essential role of the intestinal microbiota in facilitating acute inflammatory responses. J Immunol 2004;173:4137-4146.

11. Sorkine P, Szold $\mathrm{O}$, Halpern $\mathrm{P}$, et al. Gut decontamination reduces bowel ischemia-induced lung injury in rats. Chest 1997;112:491-495.

12. Nazli A, Wang A, Steen O, et al. Enterocyte cytoskeleton changes are crucial for enhanced translocation of nonpathogenic Escherichia coli across metabolically stressed gut epithelia. Infect Immun 2006;74: 192-201.

13. Chin AC, Teoh DA, Scott KG, et al. Strain-dependent induction of enterocyte apoptosis by Giardia lamblia disrupts epithelial barrier function in a caspase-3-dependent manner. Infect Immun 2002;70: 3673-3680.

14. Yu LC, Flynn AN, Turner JR, et al. SGLT-1-mediated glucose uptake protects intestinal epithelial cells against LPS-induced apoptosis and barrier defects: a novel cellular rescue mechanism? FASEB J 2005; 19:1822-1835.

15. An S, Hishikawa $Y$, Koji T. Induction of cell death in rat small intestine by ischemia reperfusion: differential roles of Fas/Fas ligand and $\mathrm{Bcl}-2 /$ Bax systems depending upon cell types. Histochem Cell Biol 2005; 123:249-261.

16. Higa OH, Parra ER, Ab'Saber AM, et al. Protective effects of ascorbic acid pretreatment in a rat model of intestinal ischemia-reperfusion injury: a histomorphometric study. Clinics 2007;62:315-320.

17. Sukhotnik I, Brod V, Lurie M, et al. The effect of $100 \%$ oxygen on intestinal preservation and recovery following ischemia-reperfusion injury in rats. Crit Care Med 2009;37:1054-1061.

18. Scheepers A, Joost HG, Schurmann A. The glucose transporter families SGLT and GLUT: molecular basis of normal and aberrant function. JPEN J Parenter Enteral Nutr 2004;28:364-371.

19. Yu LC, Turner JR, Buret AG. LPS/CD14 activation triggers SGLT-1mediated glucose uptake and cell rescue in intestinal epithelial cells via early apoptotic signals upstream of caspase-3. Exp Cell Res 2006; 312:3276-3286.

20. Yu LC, Huang CY, Kuo WT, et al. SGLT-1-mediated glucose uptake protects human intestinal epithelial cells against Giardia duodenalisinduced apoptosis. Int J Parasitol 2008;38:923-934.

21. Shiue $H$, Musch MW, Wang $Y$, et al. Akt2 phosphorylates ezrin to trigger NHE3 translocation and activation. J Biol Chem 2005;280: 1688-1695.

22. Bouchard V, Harnois C, Demers MJ, et al. B1 integrin/Fak/Src signaling in intestinal epithelial crypt cell survival: integration of complex regulatory mechanisms. Apoptosis 2008;13:531-542.

23. Chang F, Lee JT, Navolanic PM, et al. Involvement of PI3K/Akt pathway in cell cycle progression, apoptosis, and neoplastic transformation: a target for cancer chemotherapy. Leukemia 2003;17:590-603.

24. Bai D, Ueno L, Vogt PK. Akt-mediated regulation of NFkappaB and the essentialness of NFkappaB for the oncogenicity of PI3K and Akt. Int J Cancer 2009;125:2863-2870.

25. Dan HC, Baldwin AS. Differential involvement of IkappaB kinases alpha and beta in cytokine- and insulin-induced mammalian target of rapamycin activation determined by Akt. J Immunol 2008;180:7582-7589.

26. Liang J, Slingerland JM. Multiple roles of the PI3K/PKB (Akt) pathway in cell cycle progression. Cell Cycle 2003;2:339-345. 
27. Urbich C, Knau A, Fichtlscherer S, et al. FOXO-dependent expression of the proapoptotic protein Bim: pivotal role for apoptosis signaling in endothelial progenitor cells. FASEB J 2005;19:974-976.

28. Yu LC, Montagnac G, Yang PC, et al. Intestinal epithelial CD23 mediates enhanced antigen transport in allergy: evidence for novel splice forms. Am J Physiol Gastrointest Liver Physiol 2003;285:G223-G234.

29. Wang W, Smail N, Wang $P$, et al. Increased gut permeability after hemorrhage is associated with upregulation of local and systemic IL-6. J Surg Res 1998;79:39-46.

30. Hsiao JK, Huang CY, Lu YZ, et al. Magnetic resonance imaging detects intestinal barrier dysfunction in a rat model of acute mesenteric ischemia/reperfusion injury. Invest Radiol 2009;44:329-335.

31. Selvaraj SK, Prasadarao NV. Escherichia coli K1 inhibits proinflammatory cytokine induction in monocytes by preventing NF-kappaB activation. J Leukoc Biol 2005;78:544-554.

32. Murphy AJ, Guyre PM, Pioli PA. Estradiol suppresses NF-kappa B activation through coordinated regulation of let-7a and miR-125b in primary human macrophages. J Immunol 2010;184:5029-5037.

33. Funda DP, Tuckova L, Farre MA, et al. CD14 is expressed and released as soluble CD14 by human intestinal epithelial cells in vitro: lipopolysaccharide activation of epithelial cells revisited. Infect Immun 2001;69:3772-3781.

34. Suzuki M, Hisamatsu T, Podolsky DK. Gamma interferon augments the intracellular pathway for lipopolysaccharide (LPS) recognition in human intestinal epithelial cells through coordinated up-regulation of LPS uptake and expression of the intracellular Toll-like receptor 4-MD-2 complex. Infect Immun 2003;71:3503-3511.

35. Khanna A, Rossman JE, Fung $\mathrm{HL}$, et al. Intestinal and hemodynamic impairment following mesenteric ischemia/reperfusion. J Surg Res 2001;99:114-119.

36. Sun $Z$, Wang $X$, Deng $X$, et al. The influence of intestinal ischemia and reperfusion on bidirectional intestinal barrier permeability, cellular membrane integrity, proteinase inhibitors, and cell death in rats. Shock 1998;10:203-212.

37. Hall JL, Chatham JC, Eldar-Finkelman $\mathrm{H}$, et al. Upregulation of glucose metabolism during intimal lesion formation is coupled to the inhibition of vascular smooth muscle cell apoptosis. Role of GSK3beta. Diabetes 2001;50:1171-1179.

38. Russo VC, Kobayashi K, Najdovska S, et al. Neuronal protection from glucose deprivation via modulation of glucose transport and inhibition of apoptosis: a role for the insulin-like growth factor system. Brain Res 2004:1009:40-53.
39. Sun $\mathrm{D}$, Nguyen $\mathrm{N}$, DeGrado TR, et al. Ischemia induces translocation of the insulin-responsive glucose transporter GLUT4 to the plasma membrane of cardiac myocytes. Circulation 1994:89:793-798.

40. Wofford JA, Wieman HL, Jacobs SR, et al. IL-7 promotes Glut1 trafficking and glucose uptake via STAT5-mediated activation of Akt to support T-cell survival. Blood 2008;111:2101-2111.

41. Zhao H, Shiue H, Palkon S, et al. Ezrin regulates NHE3 translocation and activation after Na+-glucose cotransport. Proc Natl Acad Sci USA 2004;101:9485-9490.

42. LoPiccolo J, Blumenthal GM, Bernstein WB, et al. Targeting the PI3K/Akt/ mTOR pathway: effective combinations and clinical considerations. Drug Resist Updat 2008;11:32-50.

43. Danial NN, Gramm CF, Scorrano L, et al. BAD and glucokinase reside in a mitochondrial complex that integrates glycolysis and apoptosis. Nature 2003;424:952-956

44. Danial NN. BAD: undertaker by night, candyman by day. Oncogene 2008;27(Suppl 1):S53-S70.

45. Potoka DA, Nadler EP, Zhou X, et al. Inhibition of NF-kappaB by IkappaB prevents cytokine-induced NO production and promotes enterocyte apoptosis in vitro. Shock 2000;14:366-373.

46. Egan L, Eckmann L, Greten FR, et al. IkappaB-kinasebeta-dependent NF-kappaB activation provides radioprotection to the intestinal epithelium. Proc Natl Acad Sci USA 2004;101:2452-2457.

47. Nenci A, Becker C, Wullaert A, et al. Epithelial NEMO links innate immunity to chronic intestinal inflammation. Nature 2007;446: 557-561.

48. Kellett GL, Helliwell PA. The diffusive component of intestinal glucose absorption is mediated by the glucose-induced recruitment of GLUT2 to the brush-border membrane. Biochem J 2000;350(Part 1):155-162.

49. Kellett GL. The facilitated component of intestinal glucose absorption. J Physiol 2001;531(Part 3):585-595.

50. Palazzo M, Gariboldi S, Zanobbio L, et al. Sodium-dependent glucose transporter-1 as a novel immunological player in the intestinal mucosa. J Immunol 2008;181:3126-3136.

51. Fearon KC, Ljungqvist $\mathrm{O}$, Von Meyenfeldt $\mathrm{M}$, et al. Enhanced recovery after surgery: a consensus review of clinical care for patients undergoing colonic resection. Clin Nutr 2005;24:466-477.

52. Martindale RG, Maerz LL. Management of perioperative nutrition support. Curr Opin Crit Care 2006;12:290-294.

53. Soop M, Nygren J, Thorell A, et al. Preoperative oral carbohydrate treatment attenuates endogenous glucose release 3 days after surgery. Clin Nutr 2004;23:733-741. 